\title{
PRONAF E INCLUSÃO PRODUTIVA DOS AGRICULTORES FAMILIARES: ESTUDO DE CASO NO ESTADO DO TOCANTINS ${ }^{1}$
}

\author{
PRONAF AND PRODUCTIVE INCLUSION OF FAMILY FARMERS: \\ CASE STUDY IN THE STATE OF TOCANTINS
}

\section{PRONAF E INCLUSIÓN PRODUCTIVA DE LOS AGRICULTORES FAMILIARES: ESTUDIO DE CASO EN EL ESTADO DE TOCANTINS}

\author{
Diego Neves de Sousa ${ }^{2}$ \\ http://orcid.org/0000-0003-3124-5150 \\ Paulo André Niederle ${ }^{3}$ \\ http://orcid.org/0000-0002-7566-5467
}

Submissão: 24/04/2020 / Aceito: 23/06/2020

\begin{abstract}
Resumo
Este artigo analisa os impactos do Pronaf à inclusão produtiva dos agricultores familiares do estado do Tocantins na percepção de mediadores que atuam com este público. A pesquisa é qualitativa e fundamenta-se em informações coletadas por meio de entrevistas realizadas em 2018. Os resultados apontam que o Pronaf é uma das principais políticas de inclusão produtiva na perspectiva dos entrevistados. No entanto, isto somente se explica na medida em que a compreensão de inclusão produtiva dos mediadores está atrelada a uma visão modernizadora e produtivista, a qual não coincide com o referencial das políticas públicas de inclusão produtiva da agricultura familiar que prevaleceram entre 2002 e 2016.
\end{abstract}

Palavras-chave: Políticas públicas. Mediadores sociais. Agricultura familiar. Transferência de Tecnologia.

\begin{abstract}
This article analyzes the impacts of the Pronaf in terms of productive inclusion of family farmers in the state of Tocantins in the perception of mediators who work with this audience. The research is qualitative and is based on information collected through interviews conducted in 2018. The results show that Pronaf is one of the main policies for productive inclusion from the perspective of the interviewees. However, this is only explained to the extent that the mediators' understanding of productive inclusion is linked to a modernizing and productivist vision, which does not coincide with the benchmark of

\footnotetext{
${ }^{1}$ Este trabalho foi desenvolvido no âmbito do projeto "Inclusão produtiva, mercados e políticas públicas para os agricultores familiares e suas organizações cooperativas no Tocantins: (des)conexões entre referenciais, ideias e práticas", financiado pelo Conselho Nacional de Desenvolvimento Científico e Tecnológico (CNPq) e Serviço Nacional de Aprendizagem do Cooperativismo (Sescoop).

2 Doutor em Desenvolvimento Rural (UFRGS), analista da Embrapa Pesca e Aquicultura, Palmas, Tocantins, Brasil. E-mail: diego.sousa@embrapa.br

${ }^{3}$ Doutor em Ciências Sociais (CPDA/UFRRJ), Professor da Universidade Federal do Rio Grande do Sul
} (UFRGS), Porto Alegre, Rio Grande do Sul, Brasil. E-mail: pauloniederle@ gmail.com
\end{abstract}


public policies for productive inclusion of family farmers that prevailed between 2002 and 2016.

Keywords: Public policies. Social mediators. Family farming. Technology transfer.

\section{Resumen}

Este artículo analiza los impactos del Pronaf en términos de inclusión productiva de los agricultores familiares en el estado de Tocantins en la percepción de los mediadores que trabajan con este público. La investigación es cualitativa y se ampara en la información recopilada a través de entrevistas realizadas en 2018. Los resultados demuestran que Pronaf es una de las principales políticas para la inclusión productiva desde la perspectiva de los entrevistados. Sin embargo, esto solo puede explicarse en la medida en que la comprensión de los mediadores sobre la inclusión productiva está vinculada a una visión modernizadora y productivista, que no coincide con el punto de referencia de las políticas públicas de inclusión productiva de la agricultura familiar que prevalecieron entre 2002 y 2016.

Palabras chave: Políticas públicas. Mediadores sociales. Agricultura familiar. Transferencia de tecnología.

\section{INTRODUÇÃO}

Ao longo do percurso de reconhecimento da agricultura familiar, diversas políticas públicas foram formuladas no Brasil com o intuito de garantir a reprodução social desta categoria e, sobretudo, consolidar seu papel como produtora de alimentos e geradora de empregos (NIEDERLE; FIALHO; CONTERATO, 2014; PICOLOTTO, 2014; ESQUERDO; BERGAMASCO, 2014; GRISA; SCHNEIDER, 2014). Dentre as principais ações governamentais realizadas, destaca-se a criação, em 1995, do Programa Nacional de Fortalecimento da Agricultura Familiar (Pronaf), o qual se tornou uma das ações públicas de maior capilaridade nacional, estando presente em quase todos os municípios brasileiros (GRISA; CHECHI, SANGUINET, 2018).

O Pronaf foi a primeira política agrícola do país direcionada especificamente aos agricultores familiares com o intuito de liberar crédito rural para a capitalização das unidades familiares "em transição" - as quais se encontravam parcialmente inseridas nos circuitos de inovação tecnológica e de mercado - tendo em vista torná-las "consolidadas" (FAO/INCRA, 1994). Ao longo da sua história, o programa privilegiou modelos produtivos convencionais com baixa capacidade de absorção de mão de obra, alto grau de especialização e integrados aos mercados convencionais (GAZOLLA; SCHNEIDER, 2013). Isto refletiu no maior volume de investimentos nas regiões Sul e Sudeste do país, 
onde o processo de modernização da agricultura havia avançado mais rapidamente desde a década de 1960. Com efeito, nestas regiões o financiamento do Pronaf direcionou-se fundamentalmente a commodities como soja, café e milho (GRISA; WESZ JUNIOR; BUCHWEITZ, 2014).

Desde seu surgimento, críticas e reivindicações demandaram que o Pronaf fosse readequado para atender aos agricultores mais empobrecidos. Tais modificações foram feitas gradualmente, sendo a primeira no ano de 1997, com a criação do "Pronafinho", linha que beneficiou agricultores situados abaixo da linha da pobreza. Posteriormente foram criados subgrupos de públicos beneficiários de acordo com a renda e também linhas temáticas específicas de financiamento, tais como: Pronaf Mulher, Jovem, Agroecologia, Agroindústria, Semiárido, Eco, Florestas, Mais Alimentos, Custeio, dentre outras. Mesmo assim, o atendimento aos agricultores "periféricos" e aos povos tradicionais continuou muito aquém do suporte dado à inserção de agricultores familiares capitalizados nos mercados convencionais e modernos (WANDERLEY, 2014).

Este artigo tem como objetivo analisar os impactos do Pronaf em termos de inclusão produtiva dos agricultores familiares do estado do Tocantins na percepção de mediadores que atuam com este público. Para tanto, buscou-se identificar as modalidades que são acessadas e quais públicos acessam; os cultivos agropecuários priorizados; o referencial de política pública; e as particularidades da execução do Pronaf no Tocantins, um dos estados brasileiros com os mais elevados níveis de pobreza e insegurança alimentar da população rural e onde, portanto, existe uma importante demanda por políticas de inclusão produtiva.

A pesquisa que embasou a construção deste texto foi de cunho qualitativo e baseouse fundamentalmente na realização de oitenta entrevistas semiestruturadas com mediadores sociais que atuam com os agricultores familiares e suas organizações no estado do Tocantins, região norte do país. A coleta de dados foi realizada no ano de 2018 em 22 municípios tocantinenses contemplando 28 instituições que atuam direta e indiretamente com os públicos da agricultura familiar. Para complementar utilizou-se de dados secundários para contextualizar quantitativamente a execução do Pronaf no estado.

O artigo está organizado em cinco seções, além desta introdução. A segunda seção retrata por meio de dados estatísticos a realidade do Pronaf no Tocantins. Na terceira é apresentado o estado da arte dos estudos sobre o Pronaf e as possibilidades de inclusão 
produtiva da agricultura familiar. A terceira seção apresenta os resultados propriamente ditos da pesquisa, na qual se destaca que o Pronaf é uma das principais políticas de inclusão produtiva na perspectiva dos entrevistados. No entanto, isto somente se explica na medida em que a própria compreensão de inclusão produtiva dos mediadores também está atrelada a uma visão modernizadora e produtivista, a qual não coincide necessariamente com o referencial das políticas públicas de inclusão produtiva da agricultura familiar. Na quarta seção são apontadas as principais conclusões do estudo.

\section{Panorama do Pronaf no Tocantins}

Esta seção apresenta a situação do Pronaf no estado do Tocantins no período de 2013 a 2019. De acordo com os dados disponibilizados pelo Bacen (2020) relativos ao Pronaf custeio, o número de contratos da atividade pecuária é seis vezes maior que o da agrícola. Se tomarmos como referência a área de produção financiada e o valor total do empréstimo rural, essa diferença é da ordem de quatro vezes a mais para a pecuária. Por sua vez, em relação ao Pronaf investimento também é significativo a diferença entre a atividade agrícola e pecuária, sendo esta aproximadamente cinquenta vezes mais expressiva em termos de número de contratos, área de produção financiada e valor total financiado (Tabela 1). Isto demonstra que, no Tocantins, os recursos de custeio e investimento do Pronaf foram majoritariamente direcionados para a pecuária, o que se explica por este ser um dos estados brasileiros com maior tradição na criação de bovinos de corte (TOCANTINS, 2019).

Tabela 1 - Quantidade e valor dos contratos do Pronaf por atividade no Tocantins entre 2013 e 2019.

\begin{tabular}{l|l|l|l|l|ll}
\hline \multirow{2}{*}{ Atividade } & \multicolumn{4}{|c}{ Custeio } & \multicolumn{2}{c}{ Investimento } \\
\cline { 2 - 7 } & Área & $\begin{array}{l}\text { Quant. } \\
\text { contratos }\end{array}$ & Valor & Área & $\begin{array}{l}\text { Quant. } \\
\text { contratos }\end{array}$ & Valor \\
\hline Agrícola & $8.426,92$ & 997 & $27.831 .325,88$ & $3.794,52$ & 1.026 & $23.766 .445,15$ \\
\hline Pecuária & $33.725,27$ & 5.991 & $112.216 .623,02$ & $19.416,44$ & 50.880 & $1.100 .778 .905,44$ \\
\hline Total & $42.152,19$ & 6.988 & $140.047 .498,90$ & $23.210,96$ & 51.906 & $1.124 .545 .350,59$ \\
\hline
\end{tabular}

Fonte: Bacen, 2020. 
Ao analisar a distribuição para os diferentes públicos da agricultura familiar beneficiários do Pronaf, verifica-se que os pescadores e os aquicultores foram os que tiveram maior número de contratos firmados entre 2013 e 2019. Isto é explicado pelo investimento feito pelo governo estadual na cadeia do pescado, a qual foi impulsionada pela instalação, em Palmas, de uma unidade da Empresa Brasileira de Pesquisa Agropecuária (Embrapa) que tem a missão nacional de atuar na área da pesca e da aquicultura. No geral, conforme demonstra a Tabela 2, constata-se baixo acesso das comunidades tradicionais.

Tabela 2 - Quantidade de contratos dos beneficiários da agricultura familiar entre 2013 e 2019.

\begin{tabular}{l|c}
\hline Público & Quantitativo de contratos \\
\hline Aquicultor & 75 \\
\hline Extrativista & 9 \\
\hline Indígena & 35 \\
\hline Pescador & 211 \\
\hline Quilombola & 6 \\
\hline Silvicultor & 48 \\
\hline Fonte: Bacen, 2020. &
\end{tabular}

Em termos de área cultivada, dentre as principais cadeias produtivas agrícolas que o Pronaf financiou no Tocantins sobressaem soja, milho e arroz, como pode ser visto na Tabela 3. Como destacamos acima, a priorização destas commoditties ratifica as conclusões de outros acerca da incapacidade do Pronaf em promover uma alteração da matriz produtiva da agricultura familiar que privilegiasse cultivos regionais de alimentos. Isso se torna ainda mais evidente na medida em que, em relação às modalidades alternativas do Pronaf (Jovem, Agroecologia e Mulher etc.), em todo o Estado houve apenas quatro contratos efetivados, todos na modalidade Pronaf Mulher.

Tabela 3 -Quantidade e valor dos contratos de Pronaf por produto no Tocantins entre 2013 e 2019.

\begin{tabular}{l|r|r|r}
\hline \multicolumn{1}{|c|}{ Produto } & Área Financiada & Quantidade & \multicolumn{1}{c}{ Valor } \\
\hline SOJA & $4.650,04$ & 170 & $13.911 .507,96$ \\
\hline MILHO & 505,18 & 126 & $1.726 .021,99$ \\
\hline ARROZ & $2.875,58$ & 124 & $5.907 .241,69$ \\
\hline MANDIOCA & 303,71 & 406 & $3.278 .435,90$ \\
\hline BANANA & 2,46 & 5 & $39.532,54$ \\
\hline ABACAXI & 65,55 & 119 & $2.487 .654,90$ \\
\hline
\end{tabular}

Fonte: Bacen, 2020. 


\section{Pronaf E AS POSSIBILIDAdES DE INCLUSÃo PRODUTIVA DA AGRICULTURA FAMILIAR}

Com uma narrativa pautada pelo elevado custo da produção e a limitada liberação de crédito rural que impedia os agricultores de se manterem no campo, além de estarem à margem do processo de desenvolvimento e da modernização conservadora, o Estado instituiu oficialmente o Pronaf pelo Decreto n. ${ }^{\circ}$ 1.946, de 28 de junho de 1996, com a proposta de estabelecer um "novo padrão de desenvolvimento sustentável que vise ao alcance de níveis de satisfação e bem-estar de agricultores e consumidores, no que se refere às questões econômicas, sociais e ambientais, produzindo um novo modelo agrícola nacional” (BRASIL, 1996, p. 11). Assim, os representantes (movimentos sociais, sindicatos e sociedade civil organizada) da agricultura familiar passaram a reivindicar maior atenção do Estado por políticas diferenciadas à esta categoria a fim de viabilizar a permanência dos agricultores nas atividades produtivas.

Direcionado a diversos serviços ofertados de financiamento da atividade agropecuária, o Pronaf passou a ser o principal instrumento de apoio e inclusão produtiva à agricultura familiar utilizado para promover este proposto "novo padrão" de desenvolvimento no meio rural brasileiro. Inicialmente, a proposta seria atender parcela de agricultores aptos à transição modernizante (GUANZIROLI et al., 1994), não contemplando os agricultores "periféricos". No entanto, a criação do Pronaf contribuiu para o reconhecimento da categoria agricultura familiar como um todo e, em vista disso, o Programa aumentou o portfólio de "produtos", segmentou seus beneficiários em grupos (A, B, C, D e E) e passou a atender novas demandas dos movimentos sociais com a criação de modalidades específicas de acesso (AQUINO; SCHNEIDER, 2011).

Os primeiros impactos do Pronaf em termos de inclusão produtiva no meio rural brasileiro foram notáveis. As primeiras pesquisas apontaram que o Programa teve a capacidade de estabilizar e manter empregos no campo (IBASE, 1999), bem como proporcionar substancialmente o aumento do nível tecnológico e a produtividade dos estabelecimentos agrícolas (FECAMP, 2002). Ademais, Aquino e Schneider (2011) postulam que os impactos socioeconômicos do Pronaf não se resumem apenas à propriedade ou aos espaços rurais, mas também na dinamização do meio urbano em virtude da circulação dos recursos obtidos pelos beneficiários no comércio local. 
Entretanto, apesar de se verificar explicitamente impactos econômicos desta política de crédito, ela não tem sido capaz de proporcionar mudanças mais efetivas no padrão agrícola. Em geral, o Pronaf mantém e incentiva um modelo produtivista e convencional de agricultura (AQUINO; SCHNEIDER, 2011). Com efeito, lideranças sociais históricas dos movimentos ecologistas e agrários, tais como Jean Marc von der Weid, ligado à AS-PTA, e Sergio Gorgen, da Via Campesina, fazem duras críticas ao Pronaf:

[...] a expansão do PRONAF funcionou como mola mestra para a disseminação da lógica técnica e econômica do agronegócio em meio às unidades familiares por isso ganhando o nome de agronegocinho. Isso significou um aumento das áreas de monoculturas, a perda da diversidade dos sistemas produtivos, o emprego crescente de insumos comerciais (sementes, adubos químicos, agrotóxicos) e maquinário e equipamentos motomecanizados. Esse mergulho na modernização agrícola levou os agricultores familiares a uma crescente dependência dos mercados de capitais (bancos) e de mercados de produtos agrícolas dominados por agentes monopolísticos (empresas agroindustriais, grandes atacadistas, etc.). (WEID, 2010, p. 4).

O Pronaf vive sua fase de esgotamento como política pública massiva de ascensão social, mudança do modelo tecnológico em direção da agroecologia e universalização do acesso. Nos últimos anos o Pronaf foi sequestrado pela lógica bancária, transformou-se em formas de transferência de lucros para as indústrias de tratores e máquinas agrícolas, de agrotóxicos, de adubos químicos e multinacionais das sementes transgênicas. Afastou-se da lógica camponesa e fortalece o agronegócio da classe média rural e da indústria de venenos. (LEAL; GORGEN, 2015, itálico nosso).

Outros obstáculos que foram identificados e que limita a institucionalização por completa desta política pública são atreladas aos seguintes fatores: a) apesar do recurso disponibilizado ter indicado uma tendência de crescimento, este nem sempre atende as reais necessidades dos agricultores, em comparação ao processo de exclusão a que este público foi submetido durante o desenvolvimento da agricultura brasileira; b) os agentes financeiros que operam o Pronaf exigem garantias nem sempre compatíveis com a realidade do agricultor familiar, o que cria distorções que levam a níveis elevados de concentração dos recursos em algumas regiões e/ou produtos; c) a dotação orçamentária do Pronaf pode sofrer cortes sequenciais e, cada vez mais, está dependente de uma única fonte de recursos; d) a operacionalidade do Pronaf sofre de vícios tradicionais da burocracia dos órgãos públicos (MATTEI, 2005).

Ao buscar entender como o Pronaf tem apresentado dificuldades em diversificar os meios de vida das famílias rurais e promover inovações tecnológicas visando contrapor à 
lógica do modelo produtivista que vigora no campo, Aquino e Shneider (2011) sugerem que o incentivo do crédito rural tem se orientado mais para massificar o quantitativo de contratos assinados do que propriamente para promover transformações sociais na realidade dos beneficiários, além de se constatar que tem beneficiado em maior grau as unidades produtivas de melhores condições socioeconômicas. Isto se percebe no modo como os recursos privilegiaram os produtores de commodities mais capitalizados que estão localizados nas regiões Sul, Sudeste e Centro-Oeste do país, o que reforça o forte viés produtivista desta política.

No entanto, análises mais regionalizadas demonstram o financiamento de uma variedade de cultivos nas diferentes regiões brasileiras. Nas regiões Norte e Nordeste o Pronaf poderia ser considerado um exemplo peculiar de como tem havido inovações importantes no programa, pois concedeu apoio a produtos característicos da agricultura familiar, como a mandioca, o feijão, o arroz e também a "outras lavouras" específicas à realidade local. Outro resultado em termos regionais é que ampliação dos recursos e contratos também têm sido superiores nessas duas regiões, embora em números absolutos mantêm-se minoritárias no acesso ao Pronaf, ainda que sejam onde se concentra a maior parte da agricultura familiar brasileira (GRISA; WESZ JUNIOR; BUCHWEITZ, 2014).

Assim, constatam-se importantes avanços na trajetória do Pronaf, tais como: "o aumento dos recursos aplicados, flexibilização das condições financeiras, ampliação dos beneficiários, simplificação das condições de acesso, expansão para novas regiões etc" e, por outro lado, concentração nas commodities (principalmente milho, soja e café) e nos agricultores familiares mais capitalizados (GRISA; WESZ JUNIOR; BUCHWEITZ, 2014, p.341). Em suma, o Pronaf possui duas "caras", pois ao mesmo tempo que busca alternativas para o fortalecimento da agricultura familiar no que se refere ao incentivo à produção para autoconsumo e, sobretudo, para a promoção da segurança alimentar, o programa tem uma lógica predominantemente direcionada à modernização conservadora e incremento do padrão produtivista (GAZOLLA; SCHNEIDER, 2005). 


\section{Potencialidades e limites de inClusão Produtiva via Pronaf na PersPectiva DOS MEDIADORES SOCIAIS}

Em vista da sua trajetória institucional, era esperado que o Pronaf se destacasse nos discursos dos entrevistados como uma das principais políticas públicas que promovem a inclusão produtiva de agricultores familiares. Os mediadores entrevistados atribuíram ao Pronaf a virtude de ter sido dividido por grupos e linhas de crédito, o que propiciou maiores chances de acesso aos agricultores que se encontram na faixa de menor renda. Para Dahrendorf (1992), as diferenças sociais são balizadas por uma concentração desigual de recursos e de poder entre dominantes e dominados, atribuindo aos indivíduos (e seus grupos sociais) posições em determinada hierarquia social, o que pode acarretar na reprodução das desigualdades sociais. Com base nesse autor, Sousa et al. (2018a) vislumbram nas prerrogativas das políticas públicas a condição de minimizar as desigualdades sociais existentes e, assim, ampliar as chances de vida dos agricultores familiares, ao gerar mobilidade social ascendente para os mesmos.

De acordo com as narrativas dos mediadores, evidencia-se que, a partir do acesso ao Pronaf, os agricultores (em especial os mais pobres) conseguiram melhorar suas condições de vida. Para um mediador, o argumento é que "têm alguns casos de agricultores que mexe com horta, depois que acessaram ao Pronaf, adquiriram um tratorzinho, um complemento, uma caminhonetinha para poder trazer a mercadoria para a feira. Então, já melhorou muito para eles" (EX28, extensionista, 2018). Por sua vez, outra mediadora relata que, "por se tratar de um financiamento que mexe diretamente no bolso, eles vão atrás, buscam investir, melhorar a infraestrutura, com o intuito de melhorar as condições de aumentar a produção" (PE01, pesquisadora, 2018).

Por outro lado, diversos entrevistados expõem que o Pronaf não é mais como antes, porque está sendo reduzida a disponibilidade de recursos financeiros, além do aumento das imposições e burocracias do banco quanto à viabilidade técnica dos projetos de financiamento dos agricultores familiares que devem estar associados a uma cultura rentável como a atividade da pecuária. Essas informações podem ser conferidas nas entrevistas a seguir: 


\begin{abstract}
não passa da porta, não interessa mais para o banco, não é importante, não é interessante trabalhar nem o crédito para a agricultura familiar, entende? Então não tem mais. Hoje é mais investido na questão do gado, para o agronegócio. Você vai fazer, por exemplo, um projeto e você vai para mandioca, melancia, porco, plantio de horta ou de outra coisa, não sai se você não botar o gado no meio (MS06, movimento social, 2018).
\end{abstract}

Se você mexer com feijão, arroz ou a mandioca, ele não tem muita sustentabilidade que venha pagar como, por exemplo, em um projeto que tiver gado (MS05, movimento social, 2018).

Olhando o Plano Safra 2017/2018, a gente percebe que ele teve um retrocesso, que nos últimos anos a quantidade de financiamentos está diminuindo, mesmo eles não pegando, tendo essa indisponibilidade até para as comunidades tradicionais, nas quais os financiamentos são menores. $\mathrm{O}$ que a gente percebe, principalmente frente aos produtores menores, a dificuldade deles é o medo do banco, o medo da dívida, o medo de perder as terras, porque é a única coisa que eles têm, principalmente, para reassentados, alguns têm, uns não, não se preocupam muito, mas os que são mais corretos, que trabalham mesmo, eles têm muita dificuldade de pagar o financiamento adquirido (PR02, professora, 2018).

Essas narrativas vão ao encontro do que também é relatado pela comunidade acadêmica. Para Bittencourt (2003, p.191), o Pronaf “é limitado pelas instituições financeiras que o operam. Esta limitação se materializa no alto custo cobrado nas operações de crédito rural e na dificuldade de atender os agricultores mais pobres”. Por sua vez, Grisa, Wesz Junior e Buchwitz (2014) corroboram este argumento ao advertirem para os empecilhos burocráticos impostos pelos bancos ao dificultarem o acesso de agricultores com níveis de renda inferiores ou que apresentam projetos de financiamento não convencionais. Enquanto isso, os mais capitalizados estão mais organizados e informados, o que contribui para a maior participação no Pronaf.

Mesmo com limitações, conforme elucida Bittencourt (2003), o Pronaf é tido como uma política exitosa por ter conseguido alcançar expressivo quantitativo de agricultores em pouco tempo, fruto da interação entre as diversas organizações sociais do campo. Para tanto é crucial realizar, ainda, mudanças no escopo desta política a fim de facilitar o acesso aos agricultores mais pobres, comunidades e populações tradicionais que continuam excluídas do processo de desenvolvimento rural (NIEDERLE, 2017). No Tocantins, os quilombolas e os indígenas são os públicos mais excluídos das políticas públicas para a agricultura familiar (SOUSA, 2019).

Ao analisar as narrativas dos mediadores sobre os impactos do Pronaf em termos de inclusão produtiva, predominaram referências mais sobre o aspecto da inclusão tecnológica do que da produção de "novidades". Este termo refere-se a mudanças que, muitas vezes, 
estão 'escondidas', na qual esta pode significar uma modificação dentro de uma prática existente ou pode consistir em uma nova prática ou, ainda, ser um novo modo de fazer ou pensar, presumivelmente com potencial para promover melhorias nas rotinas agrícolas existentes (PLOEG et al., 2004). Enquanto isso, existem mediadores que creem que a única saída para garantir a persistência de uma proporção de pequenos agricultores (e incluí-los produtivamente) é o acesso à ciência e à tecnologia conduzida pela agricultura moderna, como asseveram Navarro e Pedroso (2014) e Buainain et al. (2013), numa perspectiva de reedição da modernização agrícola. ${ }^{4}$ Com a tese pautada no produtivismo e economicismo, esses autores alegam que o foco deva ser na conversão dos agricultores familiares "em transição" para os "consolidados", sobrando aos demais as políticas sociais, para que não se somem às estatísticas sobre pobreza rural.

Nesta mesma lógica, mediadores enfatizam que a característica elementar do Pronaf é que propiciou inclusão tecnológica aos agricultores familiares, a partir do momento em que foram disponibilizados recursos financeiros para que consigam dar "saltos tecnológicos" em sua devida inserção em mercados, porque anteriormente o agricultor produzia e não tinha garantias de acesso ao mercado formal, continuando a produzir apenas para o autoconsumo. Com a introdução de novas tecnologias, o agricultor passa a incrementar sua propriedade rural com ganhos de produtividade e eficiência no uso de seus recursos.

Essas ideias também coincidem com a de um pesquisador entrevistado, para quem o Pronaf contribuiu principalmente para aqueles agricultores que não tinham acesso ao crédito e tampouco tinham renda suficiente para se auto financiar ou introduzir tecnologias na própria produção. A partir do acesso ao crédito rural houve expressivo impacto na sua produção, ao ser possível financiamento para introduzir tecnologias no sistema de produção vislumbrando aumentar a escala de produção. $\mathrm{O}$ discurso de um pesquisador ${ }^{5}$ focaliza a ideia principal de que o agricultor precisa "sair da subsistência e entrar na produção minimamente comercial" por meio da adoção de tecnologias financiadas pelo Pronaf.

\footnotetext{
4 Para Bittencourt (2003), diante da emergência do Pronaf, notou-se semelhanças e reproduções de características com o crédito rural brasileiro do período da modernização da agricultura, que privilegiou os grandes e médios agricultores, localizados nas regiões Sul, Sudeste e Centro-oeste e com produção destinada à exportação de commodities.

${ }^{5} \mathrm{O}$ mediador PE07 ressalta que outra dificuldade do agricultor era a não condição de comprar a matéria prima suficiente para uma produção robusta. Mas, com o Pronaf Custeio, foi factível sanar tal demanda.
} 
Pode-se inferir, portanto, que o Pronaf é visto, em especial pelos pesquisadores, professores, gestores e extensionistas, como uma política de inclusão com foco nos aspectos modernizantes da agricultura, haja vista que a compreensão de inclusão produtiva por esses mediadores está atrelada a uma visão mais instrumental sobre transferência de tecnologia. Prova disso é que dentre as principais cadeias produtivas que o Pronaf financiou por área no Tocantins sobressaiu as tradicionais commoditties.

Em outra perspectiva, porém bem menos mencionada nas narrativas, existem mediadores que acreditam que o Pronaf foi uma política limitada que se distanciou dos contextos de aplicação de produção de novidades ${ }^{6}$ no meio rural como, por exemplo, no fato de integrar um conjunto de processos, práticas e formas organizacionais alternativas. Exemplo disso são as dificuldades enfrentadas pelos agricultores para conduzirem práticas agroecológicas em suas propriedades. Para eles, o Pronaf esteve mais associado ao que preconiza o agronegócio, o que provocou na "transformação da agricultura familiar num agronegocinho brasileiro" (EX02, extensionista, 2018). Ao ser indagado sobre qual foi o volume de recursos que entrou no Tocantins até hoje para o Pronaf Agroecologia, a resposta foi a seguinte:

[...] insignificante! Vou ver qual o volume de recursos que entrou no Tocantins para que os produtores trabalhassem com gado de corte, a maior parte dos recursos foi para isso. Eu lembro que quando no início do Pronaf a gente acompanhava as comunidades, trabalhavam com suas roças, com policultivo, com fruteiras, só que o crédito só saia para gado e na euforia de pegar o crédito os agricultores abdicaram de sistemas sustentáveis, diversos, entendeu? Que estavam atendendo os mercados locais, as feiras e acabavam entrando numa lógica de financiamento para gado, que boa parte deles foi, só trouxe respostas negativas, porque transforma uma pequena propriedade mais de gado onde a renda reduz muito, porque tinha um monte de produtos, no decorrer do ano, uma venda direta, daqui a pouco ele passa a produzir somente bezerro. Então, no fundo, uma análise que a gente vem fazendo é isso que o formato de crédito que foi proposto, ainda proposto para agricultura familiar, em vez dele atender a demanda do fortalecimento dos sistemas de produção tradicionais acaba estimulando um sistema subalterno ao agronegócio brasileiro (EX02, extensionista, 2018).

Apontamentos também foram feitos sobre a dificuldade das agências bancárias

\footnotetext{
${ }^{6}$ É fundamental relatar que a produção de novidades surge em um contexto localizado onde têm mais chances de resultar em mudanças reais. Por isto, é crucial que não se restrinjam apenas as questões técnicas, mas que perpassem as questões atinentes aos mercados e ao consumo, assim como, sejam considerados elementos relativos as disputas e embates sociais e políticos nas localidades. Até mesmo porque a contribuição da produção de novidades na agricultura, em processos de transição sociotécnica, podem estar justamente no seu caráter radical, nos quais as inovações distanciam, desviam e confrontam as regras e trajetórias dominantes (PLOEG et al., 2004).
} 
liberarem recursos para práticas agroecológicas, pois faltam garantias financeiras por parte dos agricultores familiares. No contexto do Tocantins, não houve mediadores que apontassem algum agricultor que tivesse acessado o Pronaf Agroecologia. Foram realizadas algumas tentativas por parte dos extensionistas rurais para articular o financiamento de projeto técnico do agricultor com os interesses do banco, mas estas não foram adiante pelas dificuldades de conceder garantias. Por isso do aumento do número de contratos do Pronaf vinculados aos sistemas convencionais de produção, como aponta uma mediadora. Em outras palavras,

[...] nós até questionamos com os gerentes de crédito sobre essa questão de acesso ao Pronaf Agroecologia o porquê que não era liberado. Quando falamos de projeto geralmente vem um pacote, o produtor já sabe que quando é a agroecologia e como a gente trabalha com insumos da propriedade, nós trabalhamos com a parte de equilíbrio do meio ambiente. Então, não tem um resultado ainda palpável tão imediato quanto é o acesso as outras linhas de crédito, né? Então isso dificulta um pouco a segurança dos agentes de créditos liberarem isso. O banco tem meta a ser cumprida. Quando cita o Pronaf Agroecologia eles são frustrados porque não teve acesso. Essa é a minha percepção porque nós como técnicos temos que fazer um projeto para o produtor levar até o banco, né? Então, o produtor também se sente, às vezes, inseguro em fazer esse projeto de agroecologia, eles preferem já fazer outras linhas de crédito que já está pronto mesmo que eles trabalhem de forma agroecológica e com adubo orgânico, mesmo sendo um sistema convencional (EX10, extensionista, 2018).

Muitos agricultores familiares continuam empenhados em produzir alimentos saudáveis, embora sejam raros os que acessam o Pronaf Agroecologia. O estudo de Aquino, Gazolla e Schneider (2017, p.219) confirmou que, no cenário nacional, esta modalidade possui poucos recursos aplicados, baixo número de contratos e sua operacionalização é semelhante às linhas de crédito rural convencionais, pois "está fortemente arraigada nos pilares técnico-produtivos que marcam a sua criação". Outra explicação para este resultado é o desconhecimento dos agentes financeiros sobre o funcionamento do Pronaf Agroecologia e sobre a forma de avaliação da viabilidade financeira dos projetos desta área (SAMBUICHI et al., 2017). Esta situação também impacta na inserção da produção agroecológica dos agricultores familiares nos mercados institucionais que ocorre ainda de maneira pontual e fragmentada (ROSA; SVARTMAN, 2018). De modo geral, os que 
continuam com esta atividade estão “[...] por garra mesmo, por amor" (EX10, extensionista, 2018). ${ }^{7}$

Outras modalidades do Programa também foram citadas pelos extensionistas, gestores e representantes dos movimentos sociais, tais como, o Pronaf Mulher e o Pronaf Juventude. A indicação dessas modalidades por esses mediadores reflete o fato de que eles reconhecem tais grupos como fundamentais para a promoção do desenvolvimento rural, além de estarem mais próximos desses públicos em intervenções sociotécnicas. É preciso levar em consideração esse avanço na política de crédito rural, visto que essas tipologias de financiamentos ocorrem ainda que com participação minoritária nos recursos totais do Pronaf e para atores que, provavelmente, nunca antes estiveram no escopo da política pública (GRISA; WESZ JUNIOR; BUCHWEITZ, 2014).

Dessa forma, representantes dos movimentos sociais assinalam que essa inclusão foi inovadora e que tiveram os movimentos sindicais como protagonistas ao lutarem pelo reconhecimento de políticas específicas para mulheres e para a juventude, no sentido de ter um olhar diferenciado para a diversidade de públicos beneficiários no meio rural. Entretanto, no caso do Pronaf Mulher, os mediadores consideram que houve dificuldades de acessá-lo, pois durante longo período esteve atrelado à inadimplência de empréstimos feitos pelo cônjuge, o que inviabilizava o acesso. As falas como: “[...] a comprovação da renda está sempre em nome do marido!" (PR04, professora, 2018) e “[...] podemos contar quantas mulheres tiveram acesso a esse crédito!" (MS06, movimento social, 2018) retratam as insatisfações que tais mediadoras estão com os resultados obtidos por esta política no estado. Por sua vez, as políticas de crédito para a juventude também enfrentam problemas similares: "A gente pouco conseguiu alcançar, os critérios foram bastante burocráticos para acessar esse crédito, né?” (MS05, movimento social, 2018).

Com efeito, algumas narrativas se balizaram na ideia de que com o apoio do Pronaf para as melhorias na propriedade do agricultor, só faltaria a busca por mercados para escoar a produção apesar das burocracias que existem para tal. Assim, como assevera um pesquisador, "[...] depois que acessa ao Pronaf e está produzindo de uma forma ou de outra, você consegue colocar no mercado. Às vezes, você fica muito restrito porque as

\footnotetext{
7 Uma alternativa para minimizar esta condição está na esfera da Política Estadual de Agroecologia e Produção Orgânica na qual está em tramitação na Assembleia Legislativa do Tocantins. Trata-se, portanto, de forte ligação das atividades de inclusão produtiva com as práticas agroecológicas como forma de minimizar a exclusão dos agricultores familiares no meio rural.
} 
questões burocráticas ou regulamentais e de governo travam muito" (PE04, pesquisador, 2018). Os mediadores (principalmente os extensionistas e gestores) chegam à conclusão que o Pronaf deve ser articulado com o suporte de outras políticas de desenvolvimento rural, especialmente aquelas que têm o foco na comercialização. Uma das explicações é que “[...] não basta simplesmente o governo investir no crédito, tem que ter o apoio também para comercializar porque os agricultores produzem, mas têm dificuldades de acessar o mercado e quando a gente vai tratar de mercado sabe que têm mercados $e$ mercados"(EX04, extensionista, 2018). Também há mediadores que postulam que o Pronaf teria maior eficácia se articulado com o serviço de assistência técnica e extensão rural, pois o agricultor consegue ter avanços de produtividade e gerir seus próprios produtos para que possam chegar com eficiência no mercado.

No entanto, estudos revelam uma desarticulação entre as políticas públicas para a agricultura familiar (GRISA; WESZ JUNIOR; BUCHWEITZ, 2014; GRISA; CHECHI; SANGUINIT, 2018). Em virtude disso, a articulação é feita pelos mediadores (especialmente os extensionistas, pesquisadores e professores), os quais tentam associar o Pronaf com o fomento a tecnologias para o sistema produtivo, o apoio da política de assistência técnica e a inserção nas Compras Governamentais (PAA e Pnae). Assim, se complementa o ciclo da inclusão produtiva: "[...] ao iniciar com o Pronaf, passa pela assistência técnica e depois se complementa com o acesso ao mercado" (EX04, extensionista, 2018). Desse modo, o processo de inclusão produtiva é entendido como diversas ações coordenadas que dão suporte para a efetividade de determinada cadeia produtiva (fora e dentro da porteira).

Os mediadores associam a ideia de inclusão à política de crédito, uma vez que é de suma importância o acesso a recursos financeiros para melhorias no sistema produtivo. $\mathrm{Na}$ verdade, todos os grupos de mediadores entrevistados têm o Pronaf como referência principal de política pública de inclusão produtiva. Explicam, ainda, que devido às inúmeras tipificações de públicos beneficiários, tal política contribui no sentido de ser mais inclusiva, ao fomentar a produtividade daqueles agricultores que têm vocação com a terra. De modo geral, essa política de crédito favorece os agricultores mais pobres para que possam adquirir novas tecnologias e, assim, permite que eles possam competir com aqueles que têm mais condições. 
Como destacamos acima, dentre as principais políticas públicas para a agricultura familiar que foram consideradas "de inclusão produtiva" pelos mediadores entrevistados, o Pronaf se destacou por ter sido a primeira política criada para a agricultura familiar. A partir deste fato, os mediadores entrevistados nesta pesquisa, perceberam maior preocupação do Estado com esta categoria sociopolítica, embora notem que houve uma série de problemas na concepção de tal política, o que resultou em diferentes modificações desde sua implementação. As palavras de um mediador sumarizam que "[...] houve um esforço do Estado, mas isso está muito aquém da demanda da agricultura familiar brasileira por politica de crédito" (EX02, extensionista, 2018).

\section{CONSIDERAÇÕES FINAIS}

O Pronaf destacou-se nos discursos dos entrevistados desta pesquisa como sendo uma das principais políticas públicas que promovem a inclusão produtiva de agricultores familiares. Uma das justificativas é a facilidade de ter sido dividido por grupos e linhas de crédito, o que propiciou maiores chances de acesso aos agricultores que se encontram na faixa de menor renda. Por exemplo, a referência ao Pronaf nas modalidades agroecologia e mulher associa-se à emergência de novos atores e de novidades sociotécnicas nos espaços rurais tocantinenses. Ao integrar no processo de Ater um conjunto de aprendizagens, práticas e formas organizacionais alternativas ao modelo convencional, essas novidades favorecem o reconhecimento de atores do meio rural que tinham dificuldades em acessar políticas públicas.

Por outro lado, o Pronaf não é visto como antes, porque está sendo reduzida a disponibilidade de recursos financeiros, além do aumento das imposições e burocracias do agente bancário quanto à viabilidade técnica dos projetos de financiamento dos agricultores familiares. Enquanto isso, os agricultores mais capitalizados estão em um nível maior de organização e mais informados, o que contribui para a maior participação no Pronaf. Outra crítica é que em algumas situações os financiamentos do Pronaf foram aplicados em uma finalidade contrária ao qual foi contratado o crédito rural.

Portanto, com relação à percepção dos mediadores sobre os impactos do Pronaf em termos de inclusão produtiva, predomina uma narrativa pautada pela inclusão tecnológica, 
ou seja, uma visão mais instrumental sobre transferência de tecnologia e como esta política de crédito pode potencializar o acesso do agricultor a equipamentos, máquinas e artefatos tecnológicos, ocasionando, assim, a modernização do seu sistema produtivo. Por terem uma visão mais instrumental sobre transferência de tecnologia, esses mediadores compreendem que o Pronaf tem forte ligação com a modernização da agricultura.

\section{REFERÊNCIAS}

AQUINO, J. R; GAZOLLA, M; SCHNEIDER, S. O financiamento público da produção agroecológica e orgânica no Brasil: inovação institucional, obstáculos e desafios. In: SAMBUICHI, R. H. R. et al. (org.). A política nacional de agroecologia e produção orgânica no Brasil: uma trajetória de luta pelo desenvolvimento rural sustentável. Brasília: IPEA, 2017. p. 197-227.

AQUINO, J. R; SCHNEIDER, S. 12 Anos da política de crédito do PRONAF no Brasil (1996-2008): Uma reflexão crítica. Revista de Extensão e Estudos Rurais, Viçosa, n.2, v.1, p. 309-347, 2011.

\section{BACEN - BANCO CENTRAL DO BRASIL. Matriz de Dados do Crédito Rural.}

Disponível em:<https://www.bcb.gov.br/estabilidadefinanceira/micrrural >. Acesso em 11 jun. 2020.

BITTENCOURT, G. A. Abrindo a caixa preta: o financiamento da agricultura familiar no Brasil. 2003. Dissertação (Mestrado em Economia) - Curso de Pós-Graduação em Economia, Universidade Estadual de Campinas, Campinas, 2003. BRASIL. Ministério da Agricultura e do Abastecimento. PRONAF - Programa Nacional de Fortalecimento da Agricultura Familiar. Brasília, 1996.

BUAINAIN, A. M. et al. Sete teses sobre o mundo rural brasileiro. Revista de Política Agrícola, Brasília, v. 22, n. 2, p. 105-121, 2013.

CALLON, M. Eléments pour une sociologie de la traduction: la domestication des coquilles Saint-Jacques et des marins-pêcheurs dans la baie de Saint-Brieuc. L'Anné Sociologique, Paris, n. 36, p. 169-208, 1986.

CAZELLA, A. A. et al. Políticas públicas de desenvolvimento rural no Brasil: o dilema entre inclusão produtiva e assistência social. Política \&Sociedade, Florianópolis, v. 15, n. especial, p. 49-79, 2016.

DAHRENDORF, R. O conflito social moderno: um ensaio sobre a política da liberdade. São Paulo: Zahar, 1992. 
ESQUERDO, V. F. S; BERGAMASCO, S. M. P. P. Análise sobre o acesso aos programas de políticas públicas da agricultura familiar nos municípios do Circuito das Frutas (SP). Revista de Economia e Sociologia Rural, Brasília, v. 52, p. 205-222, 2014.

FUNDAÇÃO DE ECONOMIA DE CAMPINAS - FECAMP. Estudos de caso em campo para avaliação dos impactos do Pronaf. Unicamp: Campinas, 2002. (Convênio PCT/IICA-FECAMP).

GAZOLLA, M.; SCHNEIDER, S. As duas "caras" do Pronaf: produtivismo ou fortalecimento da produção para autoconsumo? In: XLIII Congresso da Sociedade Brasileira de Economia e Sociologia Rural, 2005, Ribeirão Preto-SP. Anais do XLIII Congresso da Sociedade Brasileira de Economia e Sociologia Rural, 2005.

GAZOLLA, M; SCHNEIDER, S. Qual fortalecimento da agricultura familiar? Uma análise do Pronaf crédito de custeio e investimento no Rio Grande do Sul. Revista de Economia e Sociologia Rural, Brasília, v. 51, p. 45-68, 2013.

GRISA, C; CHECHI, L. A; SANGUINIT, E. R. A incidência de políticas públicas para a agricultura familiar no Brasil: considerações a partir dos municípios, regiões e territórios da cidadania. Revista Grifos, Chapecó, v.27, n.45, p.159-183, 2018.

GRISA, C; SCHNEIDER, S. Três gerações de políticas públicas para a agricultura familiar e formas de interação entre sociedade e Estado no Brasil. Revista de Economia e Sociologia Rural, Brasília, v. 52, p. 125-146, 2014.

GRISA, C; WESZ JUNIOR, V. J; BUCHWEITZ, V. D. Revisitando o Pronaf: velhos questionamentos, novas interpretações. Revista de Economia e Sociologia Rural, Brasília, v. 52, n.2, p. 323-346, 2014.

GUANZIROLI, C. E. et al. Diretrizes de política agrária e desenvolvimento sustentável. Brasília, DF: FAO/INCRA, 1994, 24p. (Relatório Final do Projeto UTF/BRA/036). Instituto Brasileiro de Análises Sociais e Econômicas - IBASE. Avaliação dos programas de geração de emprego e renda. Democracia Viva, edição especial, 1999.

INSTITUTO BRASILEIRO DE GEOGRAFIA E ESTATÍSTICA - IBGE. Censo Agropecuário 2017. Rio de Janeiro: IBGE, 2017. Disponível em: https://bit.ly/34kjLbb. Acesso em: 26 out. 2019.

LEAL, M.; GORGEN, S. A Hora e a Vez de um Programa Camponês. 2015. Disponível em: <http://www.mst.org.br/2015/03/23/a-hora-e-a-vez-de-um-programa-campones.html>. Acesso em 02 de março de 2020.

MATTEI, L. Impactos do Pronaf: análise de indicadores. Brasília: MDA/NEAD, 2005. (NEAD Estudos, 11). Disponível em: https://bit.ly/2RsXnbw. Acesso em: 11 abr. 2020. 
NAVARRO, Z; PEDROSO, M. T. M. A agricultura familiar no Brasil: da promessa inicial aos impasses do presente. Revista Econômica do Nordeste, Fortaleza, v. 45, p. 6-17, 2014.

NIEDERLE, P. A. Afinal, que inclusão produtiva? A contribuição dos novos mercados alimentares. In: DELGADO, G. C; BERGAMASCO, S. M. P. P. (org.). Agricultura familiar brasileira: desafios e perspectivas de futuro. Brasília: MDA, 2017. p. 166-194.

NIEDERLE, P. A.; FIALHO, M. A.; CONTERATO, M. A. A pesquisa sobre agricultura familiar no Brasil - aprendizagens, esquecimentos e novidades. Revista de Economia e Sociologia Rural, v. 52, p. 9-24, 2014.

ORGANIZAÇÃO DAS NAÇÕES UNIDAS PARA A ALIMENTAÇÃO E A AGRICULTURA - FAO; INSTITUTO NACIONAL DE COLONIZAÇÃO E REFORMA AGRÁRIA - INCRA. Diretrizes de Política Agrária e Desenvolvimento Sustentável. Brasília, Versão resumida do Relatório Final do Projeto UTF/BRA/036, 1994.

PICOLOTTO, E. L. Os atores da construção da categoria agricultura familiar no Brasil. Revista de Economia e Sociologia Rural, Brasília, v. 52, p.63-84, 2014.

PLOEG, J. D. et al. On regimes, novelties, niches and co-production. In: WISKERKE, J. S. C; PLOEG, J. D. (ed). Seeds of transition. Assen: Royal van Gorcum, 2004. p. 1-30.

ROSA, M. P; SVARTMAN, B. P. Agroecologia e políticas públicas: reflexões sobre um cenário em constantes disputas. Revista Psicologia Política, São Paulo, v.18, n.41, p. 18 $41,2018$.

SAMBUICHI, R. H. R. et al. Avaliação da execução do plano nacional de agroecologia e produção orgânica 2013-2015. In: SAMBUICHI, R. H. R. et al. (org.). A política nacional de agroecologia e produção orgânica no Brasil: uma trajetória de luta pelo desenvolvimento rural sustentável. Brasília: IPEA, 2017. p. 147-196.

SCHNEIDER, S. A importância da pluriatividade para as políticas públicas no Brasil. Revista de Política Agrícola, Brasília, n. 3, v.16, p. 14-33, 2007.

SOUSA, D. N. Mediadores sociais e políticas públicas de inclusão produtiva da agricultura familiar no Tocantins: (des)conexões entre referenciais, ideias e práticas. 2019. Tese (Doutorado em Desenvolvimento Rural) - Curso de Pós-Graduação em Desenvolvimento Rural, Faculdade de Ciências Econômicas, Universidade Federal do Rio Grande do Sul, Porto Alegre, 2019a.

SOUSA, D. N. O que se entende por inclusão produtiva dos agricultores familiares? Um estudo de revisão bibliométrica. Cadernos de Ciência \& Tecnologia, Brasília, v.36, p.1$13,2019 b$.

SOUSA, D. N; NIEDERLE, P. A. A produção científica brasileira sobre o que se entende por inclusão produtiva: um recorte temporal entre 2005 a 2016. Revista Desenvolvimento 
Social, Montes Claros, v. 1, p. 15-32, 2018.

SOUSA, D. N. et al. Programas governamentais de aquisição de alimentos da agricultura familiar no estado do Tocantins. Revista Brasileira de Gestão e Desenvolvimento Regional, Taubaté, v. 14, p. 252-264, 2018a.

SOUSA, D. N. et al. Inovação e inclusão produtiva na agricultura familiar do Tocantins. Revista Grifos, Chapecó, v.2 7, n. 45, p.204-224, 2018b.

TOCANTINS. Secretaria de Agricultura, Pecuária e Aquicultura - SEAGRO.

Pecuária.2019b. Disponível em: https://bit.ly/2HeGpb5. Acesso em 23 jan. 2020.

WANDERLEY, M. N. B. O campesinato brasileiro: uma história de resistência. Revista de Economia e Sociologia Rural, Brasília, v. 52, p. 25-44, 2014.

WEID, J-M. V. D. Agricultura familiar: sustentando o insustentável? Agriculturas, v. 7, n. 2, p. 4-7, 2010. 